\title{
West Nile virus: the Italian national transplant network reaction to an alert in the north-eastern region, Italy 2011
}

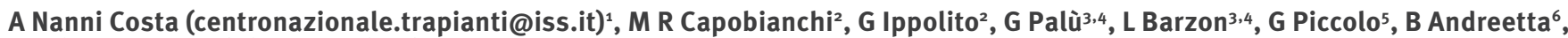
M Filippetti ${ }^{1}$, D Fehily ${ }^{1}$, L Lombardini ${ }^{1}$, P Grossi ${ }^{7}$

1. National Transplant Centre, Italian National Institute of Health, Rome, Italy

2. National Institute for Infectious Diseases (INMI) “L. Spallanzani”, Rome, Italy

3. Department of Histology, Microbiology and Medical Biotechnology, University of Padova, Italy

4. Regional Reference Centre for Infectious Diseases, Microbiology and Virology Unit, University Hospital, Padova, Italy

5. Department of Infectious Diseases, University of Insubria, Varese, Italy

6. North Italy Transplant Interregional Coordinating Transplant Centre, Ospedale Maggiore Policlinico, Milan, Italy

7. Veneto Regional Coordinating Transplant Centre, Azienda Ospedaliera di Padova, Padua, Italy

Citation style for this article:

Nanni Costa A, Capobianchi MR, Ippolito G, Palù G, Barzon L, Piccolo G, Andreetta B, Filippetti M, Fehily D, Lombardini L, Grossi P. West Nile virus: the Italian national transplant network reaction to an alert in the north-eastern region, Italy 2011.

Euro Surveill. 2011;16(41):pii=19991. Available online: http://www.eurosurveillance.org/ViewArticle.aspx?Articleld=19991

Article published on 13 October 2011

We report four cases of West Nile virus (WNV) transmission following a single multiorgan donation in north-eastern Italy. The transmissions were promptly detected by local transplant centres. The donor had been tested for WNV by nucleic acid amplification test (NAT) prior to transplantation and was negative. There were no detected errors in the nationally implemented WNV safety protocols.

\section{Case reports}

In August 2011, a multiorgan and tissue retrieval was carried out in north-eastern Italy from a donor who was a resident in the same area. The donor's organs (kidneys, lungs, heart and liver) were successfully transplanted to recipients in other Italian regions, including the north-eastern region. The donor's health status was confirmed prior to donation, by blood- and instrumental-tests and detection of markers for transmissible diseases (hepatitis B surface antigen, hepatitis C virus antibodies, human immunodeficiency virus $1 / 2$ antibody, Treponema pallidum Particle Agglutination Assay), in addition to interviews with relatives. In line with transplant procedures, the donor cause of death was not related to any transmissible disease. Moreover, due to special procedures in place for prevention of West Nile virus (WNV) in this part of Italy, a donor blood sample had tested negative for WNV by nucleic acid amplification test (NAT).

Ten days after transplantation, two patients who had each received a respective kidney, developed fever and neurological symptoms, suggestive of West Nile neuroinvasive disease. The purpose of this rapid communication is to describe how, despite testing strategies in place for WNV, transmissions occurred and how the Italian National Transplant Network responded to the WNV transmissions associated with a multiorgan transplant, in the context of negative nucleic acid amplification test (NAT) results in the donor.

\section{Background}

Due to WNV circulation and documented infections in humans in north-eastern Italy [1], several preventive measures related to WNV transmission to humans have been implemented. Since 2008, the Italian National Transplant Network, in collaboration with the regional health authorities, started an epidemiological surveillance programme in order to detect WNV in organ donors in north-eastern Italy [1-3]. Moreover, in the same area, plans are in place in the medical and veterinary fields for active surveillance and monitoring of WNV infection in animals and humans [4-7]. In addition to this epidemiological monitoring, the Italian National Transplant Network decided to perform NAT within 72 hours of donation on all donors living in areas where WNV had been demonstrated to be endemic $[1,7,8]$. These measures are carried out from 15 July to 15 November 2011 in order to prevent WNV transmission from organ and/or tissue donations to recipient patients.

\section{Laboratory investigations \\ and control measures}

On the basis of time schedules foreseen by rules and protocols issued for prevention of WNV (within 72 hours from donation) [1], virological testing was carried out on the blood sample collected before donor death by the virology laboratory of Padua University, using a NAT technique (cobas TaqScreen West Nile Virus Test - Roche). No signs of fever or malaise had been documented in the week prior to donation. The result of the test on the donor was negative. About ten days after transplant, two transplant centres reported to the Italian National Transplant Centre suspected neurological symptoms in patients who had received a kidney 
transplant from this donor. Between four and five days after transplantation, both kidney recipients had developed fever and ongoing encephalitis, symptoms compatible with WNV neuroinvasive disease $[9,10]$. The WNV NAT test performed with the same technique as with the donor, on both patients resulted positive (blood and urine samples). Following a protocol that had been successfully used in similar situations $[11,12]$, high titre West Nile intravenous immunoglobulin was only administrated to one of the two kidney recipient, since the other one had already produced anti-WNV antibodies. After the reports of suspect symptoms in the two kidney recipients, virological tests on donor materials were repeated again using the NAT technique (cobas TaqScreen West Nile Virus Test - Roche) by the virology laboratory at the National Institute for Infectious Disease "L. Spallanzani” in Rome. The negative initial test result was confirmed, whereas serological tests showed the presence of anti-WNV antibodies (immunofluorescence assay - Euroimmun Italia) (Table). After this, NAT and serological tests were performed on the further three organ recipients who had received heart, lung and liver from the same donor. The NAT results for the heart and liver recipients were negative. The NAT result of the lung recipient was positive.

Thirty seven days after transplantation, one of the kidney recipients was more critically ill than the other kidney recipient; investigations on a possible link between the severity of the clinical condition and a genetic disease affecting the first patient are ongoing. Also at 37 days after transplantation, the NAT test- negative liver and heart recipients were in good health, while the lung recipient, who tested positive for WNV, presented neurological symptoms that can possibly be ascribed to immunosuppressive therapy toxicity.

As soon as it was suspected that WNV transmission from the donor could have occurred in the organ recipients, further use of all remaining tissues from the donor was stopped.

\section{Conlusion}

When the first report of symptoms indicating suspected transmission of WNV from donor to recipient was detected ten days after the transplantation, the
Italian National Transplant Network promptly followed all communication and clinical protocols. First, the other transplant centres where the three recipients of heart, lungs and liver had been operated were alerted. At the same time, the National Transplant Centre and the Interregional Centre of competence, in cooperation with a national expert on infectious diseases (in charge of giving a "Second Opinion" on particular donation case) agreed and coordinated the clinical measures to be put in place to prevent further transmission and to insure adequate managing and care of the organ recipients. In particular, we took all therapeutic measures currently available for WNV, using stocks of plasma collected from donors positive for antibodies to WNV as a result of infections recorded in 2008 and 2009 in the north-east of our country. As no errors in safety protocols pre-donation occurred, it is assumed that virus concentration in the donor was not sufficient to be detected by the NAT technique.

The rapidly available test results and traceability of materials allowed prevention of further use of all remaining tissues from the donor. Testing the donor sample, earlier than within the required 72 hours postdonation, would not have been useful because of the likely low-level viraemia in the donor. It is however necessary to follow recommendations given in 2010 by the Italian Higher Health Council [13], that advised to screen donors by testing for viral RNA by the NAT technique within 72 hours of donation. This measure should be enhanced by the search for antibodies which should be carried out in a limited number of references laboratories, so as to ensure high quality standards. Clearly, traceability of donor organs through a national transplant network is crucial to facilitate tracing back to the donor also to other recipients of the latter, and to allow the study of suspected transmissions. In our case, rapid detection of the viral transmission facilitated the prevention of further transmissions to other tissue recipients.

\section{References}

1. Nanni Costa A, Grossi P, Porta E, Venettoni S, Fehily D. Measures taken to reduce the risk of West Nile virus transmission by transplantation in Italy. Euro Surveill.

TABLE

Molecular and serological test results for West Nile virus infection on samples from organ donor and recipients, Italy 2011 $(\mathrm{n}=6)$

\begin{tabular}{|l|l|l|}
\hline Donor & NAT test result & Antibodies determination \\
\hline First kidney recipient & Negative on blood & Positive (IgG and IgM) on blood \\
\hline Second kidney recipient & Positive on blood and spinal fluid & Positive (IgG and IgM) on blood and spinal fluid \\
\hline Heart recipient & Positive on blood and spinal fluid & Positive (IgG and IgM) on blood and spinal fluid \\
\hline Liver recipient & Negative on blood & Negative on blood \\
\hline Lung recipient & Negative on blood & Positive (IgG and IgM) on blood \\
\hline
\end{tabular}

NAT: Nucleic acid amplification test. 
2008;13(42):pii=19009. Available from: http://www. eurosurveillance.org/ViewArticle.aspx?Articleld=19009

2. Kusne S, Smilack J. Transmission of West Nile virus by organ transplantation. Liver Transpl. 2005;11(2):239-41.

3. Capobianchi MR, Sambri V, Castilletti C, Pierro AM, Rossini $\mathrm{G}$, Gaibani P et al. Retrospective screening of solid organ donors in Italy, 2009, reveals unpredicted circulation of West Nile virus. Euro Surveill. 2010;15(34):pii=19648. Available from: http://www.eurosurveillance.org/ViewArticle. aspx?Articleld $=19648$

4. Gobbi F, Napoletano G, Piovesan C, Russo F, Angheben A, Rossanese A et al. Where is West Nile fever? Lessons learnt from recent human cases in northern Italy. Euro Surveill. 2009;14(10): pii=19143. Available from: http://www. eurosurveillance.org/ViewArticle.aspx?Articleld=19143

5. Barzon L, Pacenti M, Cusinato R, Cattai M, Franchin E, Pagni S et al. Human cases of West Nile Virus Infection in north-eastern Italy, 15 June to 15 November 2010. Euro Surveill.2011;16(33):pii=19949. Available from: http://www. eurosurveillance.org/ViewArticle.aspx?Articleld=19949

6. Barzon L, Franchin E, Squarzon L, Lavezzo E, Toppo S, Martello T, et al. Genome sequence analysis of the first human West Nile virus isolated in Italy in 2009. Euro Surveill.2009; 14(44):pii=19384. Available from: http://www. eurosurveillance.org/ViewArticle.aspx?Articleld=19384

7. Rizzo C, Vescio F, DeclichS, Finarelli AC, Macini P, Mattivi $A$, et al. West Nile virus transmission with human cases in Italy, August - September 2009. Euro Surveill.2009; 14(40): pii=19353. Available from: http://www.eurosurveillance. org/ViewArticle.aspx?Articleld=19353

8. Kiberd BA, ForwardK. Screening for West Nile virus in organ transplantation: A medical decision analysis. Am J Transplant. 2004;4(8):1296-301.

9. Centers for Disease Control and Prevention (CDC). West Nile virus transmission via organ transplantation and blood transfusion - Louisiana, 2008. MMWR Morb Mortal Wkly Rep. 2009;58(45):1263-7.

10. DeSalvo D, Roy-Chaudhury P, Peddi R, Merchen T, Konijetti K, Gupta M, et al. West Nile virus encephalitis in organ transplant recipients: another high-risk group for meningoencephalitis and death. Transplantation 2004;77(3):466-9.

11. Rhee C, Eaton EF, Concepcion W, Blackburn BG. West Nile virus encephalitis acquired via liver transplantation and clinical response to intravenous immunoglobulin: case report and review of the literature. Transpl Infect Dis. 2011;13(3):312-7.

12. Morelli MC, Sambri V, Grazi GL, Gaibani P, Pierro A, Cescon M, et al. Absence of neuroinvasive disease in a liver transplant recipient who acquired West Nile virus (WNV) infection from the organ donor and who received WNV antibodies prophylactically. Clin Infect Dis. 2010;51(4):e34-7.

13. Italian Higher Health Council, Ministry of Health, Proposals to screen donors to prevent donor to recipient disease transmission. 8 June, 2010. 